\title{
Surface Photografting Polymerization of Binary Monomers Maleic Anhydride and $n$-Butyl Vinyl Ether on Polypropylene Film II. Some Mechanistical Aspects
}

\author{
Chang-Min XING, ${ }^{*, * *}$ Jian-Ping DeNG, ${ }^{*, * *}$ and Wan-Tai YANG ${ }^{*, * * \dagger}$ \\ *Department of Polymer Science, Beijing University of Chemical Technology, Beijing 100029, China \\ ${ }^{* *}$ Key Laboratory of Science and Technology of Controllable Chemical Reactions, \\ Ministry of Education, Beijing 100029, China
}

(Received April 22, 2002; Accepted August 2, 2002)

\begin{abstract}
On the basis of the previous work, another experiments were carried out to investigate the photografting polymerization of maleic anhydride (MAH)/ $n$-butyl vinyl ether ( $n$-BVE) more intensively, from which some particular characteristics related to the mechanism were found out. The activation energy of the overall polymerization (Eap) is about $5.9 \mathrm{~kJ} \mathrm{~mol}^{-1}$, while the value of the photografting polymerization (Eag) is around $29.3 \mathrm{~kJ} \mathrm{~mol}^{-1}$, which indicates that high reaction temperature would reduce the homopolymerization and accordingly favors the graft polymerization. $\mathrm{MAH}$, as a monomer, could act as a photoinitiator as well, which was deduced from the unexpected phenomenon that the photografting polymerization could perform smoothly even in the absence of photoinitiator. More experiments confirmed that the grafting efficiency reached the highest when the molar ratio of MAH to BVE was $1: 1$, from which it can be concluded that the formation of charge transfer complex (CTC) between MAH and BVE is a crucial factor leading to the high grafting efficiency. The formation of CTC was measured by UV spectra and the equilibrium constant of CTC was determined by ${ }^{1} \mathrm{H}$ NMR method. As a result, the photografting process of the binary monomers MAH/BVE was outlined.
\end{abstract}

KEY WORDS Surface Photografting Polymerization / Maleic Anhydride / n-Butyl Vinyl Ether / Charge Transfer Complex /

In the previous paper, ${ }^{1}$ the principal factors affecting the surface photografting polymerization, such as irradiation time, molar ratio of maleic anhydride (MAH) to butyl vinyl ether (BVE), monomer concentration, photoinitiators, ultraviolet (UV) and solvents, have been investigated systematically. On the basis of the above work, a series of another experiments were carried out to investigate the photografting polymerization of MAH/BVE more intensively.

In fact, the photografting system with $\mathrm{MAH} / \mathrm{BVE}$ as binary monomers, benzophenone (BP) as photoinitiator and acetone as solvent is very complicated. First of all, the reaction system is heterogeneous, and the photografting polymerization takes place merely at the liquid-solid interface between the substrate and liquid phase, so the diffusion of monomer and photoinitiator is an important process in the course of the reaction. Besides, the reaction system involves binary monomers $\mathrm{MAH}$ and BVE, which tend to form charge transfer complex (CTC). ${ }^{2}$ In this paper, we elementarily discovered some aspects related to the mechanism of the photografting of MAH/BVE by investigating the crucial effects of another factors.

\section{EXPERIMENTAL}

\section{Materials}

Commercial casting polypropylene (CPP) film, $30 \mu \mathrm{m}$ thick, with transmittance close to $100 \%$ for the UV radiation, was used as the substrate, which was first cut into circular shape of about $50 \mathrm{~mm}$ in diameter and then subjected to Soxhlet extraction with acetone for $24 \mathrm{~h}$ to remove the additives and impurities.

MAH was purified by distillation before use, and $n$-BVE was analytical grade, used without further purification. The photoinitiator BP was analytical grade, used without further purification. The solvent acetone was analytical grade, used without further purification.

\section{Photografting Polymerization Procedure}

The photografting polymerization procedure, the post-treatment of the grafted films and the definitions of the parameters are all the same as those in the previous paper. ${ }^{1}$

\section{UV Spectra}

The UV spectra of CTC between MAH and $n$ BVE was measured by UV-Visible Spectrometer (GBC

${ }^{\dagger}$ To whom correspondence should be addressed (Tel: +86-10-64432262, Fax: +86-10-64416338, E-mail: yangwt@mail.buct.edu.cn). 
Cintra 20, Australia) at $25{ }^{\circ} \mathrm{C}$. The concentration of MAH was kept constant at $1.0 \mathrm{~mol} \mathrm{~L}^{-1}$ with acetone as the solvent while that of BVE was varied from 0 to $1.0 \mathrm{~mol} \mathrm{~L}^{-1}$.

\section{NMR Spectra}

The spectra of CTC between MAH and $n$-BVE were recorded by NMR AC-80 Bruker spectrometer with deuteriochloroform $\left(\mathrm{CDCl}_{3}\right)$ as solvent and the chemical shift of the solvent $(7.24 \mathrm{ppm})$ as reference at $35^{\circ} \mathrm{C}$. The concentration of MAH was kept constant at $0.1 \mathrm{~mol} \mathrm{~L}^{-1}$, while that of BVE was varied and ensured $[\mathrm{MAH}]_{\mathrm{o}} \ll[\mathrm{BVE}]_{\mathrm{o}}$.

\section{RESULTS AND DISCUSSION}

Activation Energy of the Surface Photografting Polymerization

For general photopolymerization, the effect of temperature is not much, due to the low activation energy. For surface photografting polymerization, however, the case is quite different. The experimental results are shown in Figure 1.

The curves in Figure 1 show that the surface photografting of MAH/BVE was affected remarkably by temperature. The grafting yield and grafting efficiency both increased along with the elevation of the reaction temperature, which indicated that high reaction temperature was favorable to the photografting polymerization.

In order to further investigate the effect of reaction temperature on photografting polymerization, some kinetic parameters were calculated. Fist of all, a series of more elaborate experiments at various temperatures were carried out, in which the data of $W_{\mathrm{p}}$ and $W_{\mathrm{g}}$ of every $2 \mathrm{~s}$ (in the later period, the interval was $5 \mathrm{~s}$ ) were measured, and afterwards $C_{\mathrm{p}}$ and $Y_{\mathrm{g}}$ were calculated according to the definition in the previous article. Thus the evolutions of the photografting polymerization were exhibited more clearly, as shown in Figure 2.

Then the rates of the overall polymerization $\left(R_{\mathrm{p}}\right)$ and the grafting polymerization $\left(R_{\mathrm{g}}\right)$ can be obtained from the slopes (in the preceding $10 \mathrm{~s}$ ) of the plots $C_{\mathrm{p}} v s$. irradiation time and $Y_{\mathrm{g}} v s$. irradiation time. The results of $R_{\mathrm{p}}$ and $R_{\mathrm{g}}$ at various temperatures are summarized in Table I.

From the data in Table I, two kinetic characteristics of the photografting polymerization can be found out. 1) $R_{\mathrm{g}}<R_{\mathrm{p}}$, to speak in detail, $R_{\mathrm{g}}$ is $1 / 3-2 / 3$ of $R_{\mathrm{p}}$ in the temperature range of $30-70{ }^{\circ} \mathrm{C} ; 2$ ) The influences of the temperature on $R_{\mathrm{p}}$ and $R_{\mathrm{g}}$ are different, that is, $R_{\mathrm{p}}$ increased mildly (the value at $70{ }^{\circ} \mathrm{C}$ is only 0.35 times larger than that at $30^{\circ} \mathrm{C}$ ) while $R_{\mathrm{g}}$ increased remark-

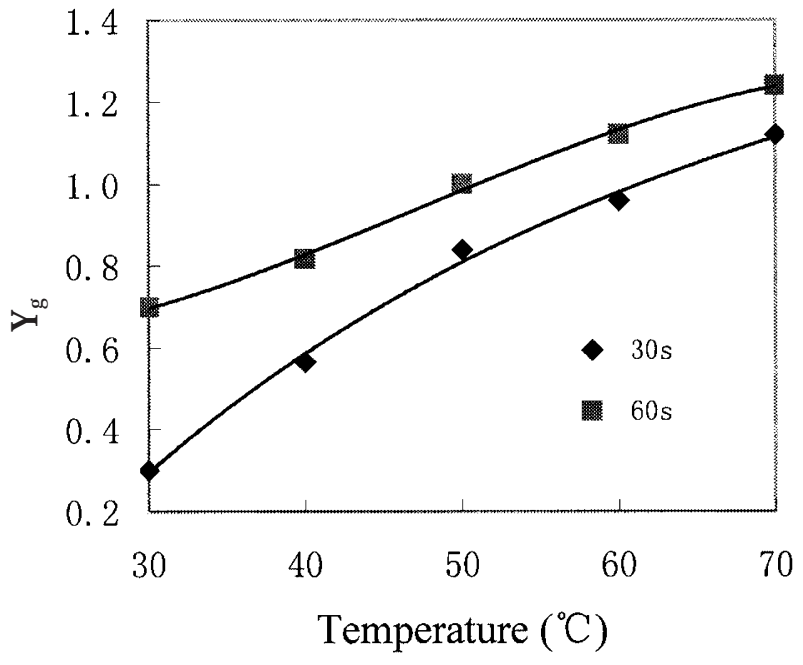

(A)

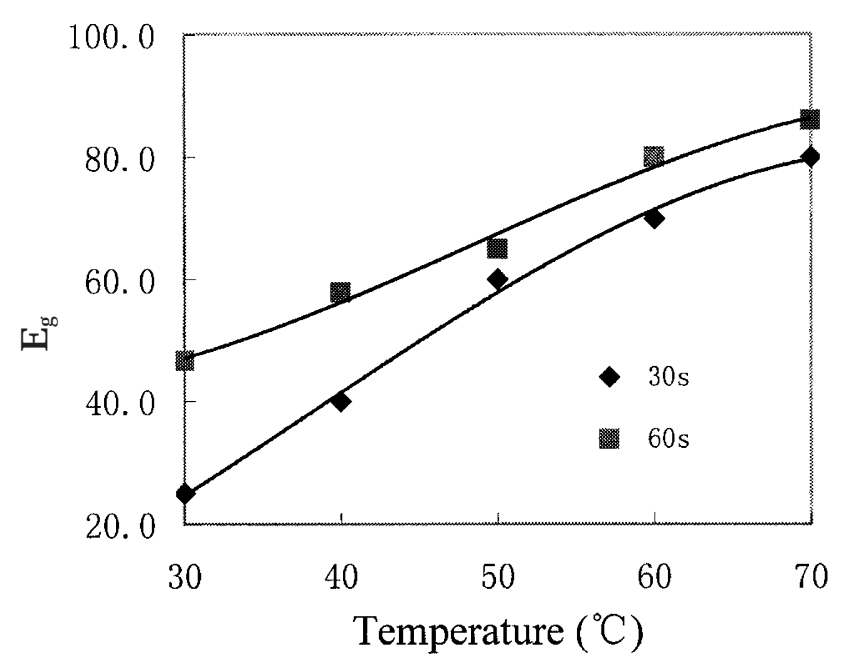

(B)

Figure 1. Effect of the reaction temperature on the grafting yield (A) and grafting efficiency (B). Molar ratio of MAH to BVE, $1: 1$; total monomer concentration, $4 \mathrm{~mol} \mathrm{~L}^{-1}$; $\mathrm{BP}$ concentration, $0.05 \mathrm{~mol} \mathrm{~L}^{-1}$; solvent, acetone; volume of reaction solution, $5 \mu \mathrm{L}$; UV intensity, $6900 \mu \mathrm{W} \mathrm{cm}^{-2}$.

Table I. Rates of the overall polymerization and graft polymerization at various temperatures*

\begin{tabular}{cccccc}
\hline & $30{ }^{\circ} \mathrm{C}$ & $40{ }^{\circ} \mathrm{C}$ & $50{ }^{\circ} \mathrm{C}$ & $60{ }^{\circ} \mathrm{C}$ & $70^{\circ} \mathrm{C}$ \\
\hline$R_{\mathrm{p}}\left(10^{-5} \mathrm{~g} \mathrm{~s}^{-1}\right)^{*}$ & 5.35 & 6.26 & 6.57 & 6.99 & 7.21 \\
$R_{\mathrm{g}}\left(10^{-5} \mathrm{~g} \mathrm{~s}^{-1}\right)$ & 1.50 & 1.64 & 2.97 & 4.99 & 5.01 \\
\hline
\end{tabular}

${ }^{*}$ Since the polymer yielded was measured by gravimetric method, $R_{\mathrm{p}}$ and $R_{\mathrm{g}}$ can be defined as $R_{\mathrm{p}}=\mathrm{d} W_{\mathrm{p}} / \mathrm{d}_{\mathrm{t}}, R_{\mathrm{g}}=\mathrm{d} W_{\mathrm{g}} / \mathrm{d}_{\mathrm{t}}$, where $W_{\mathrm{p}}$ is the weight of the total polymer yielded, $W_{\mathrm{g}}$ is the weight of the grafted polymer yielded.

ably (2.33 times) along with the elevation of the temperature.

The first characteristic indicates that the homopolymerization (in fact, the ungraft polymerization in this system is copolymerization, but we still call it homopolymerization by convention, et seq.) inevitably 


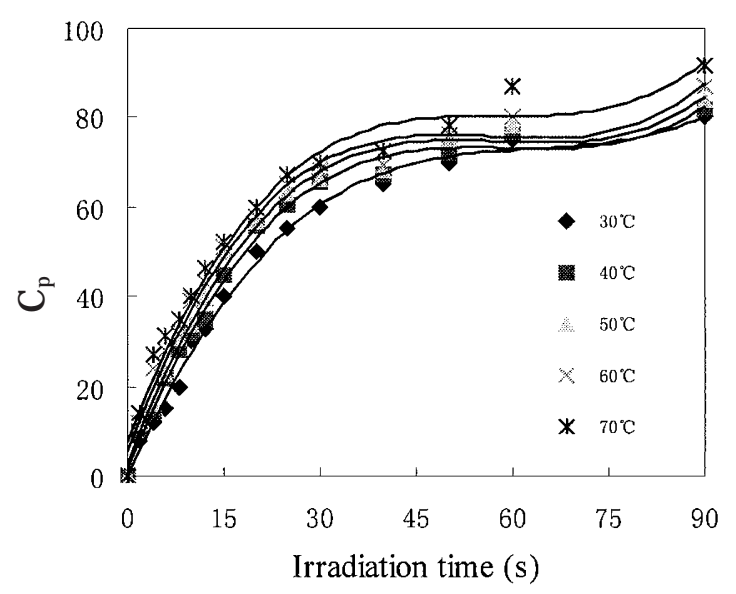

(A)

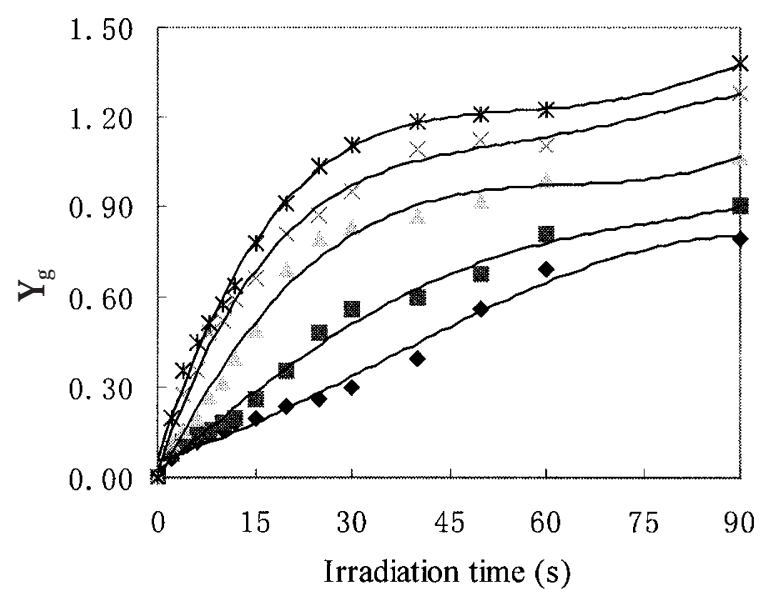

(B)

Figure 2. Evolution of the overall polymerization (A) and graft polymerization (B) at various temperatures. Molar ratio of MAH to BVE, 1 : 1; total monomer concentration, $4 \mathrm{~mol} \mathrm{~L}^{-1}$; $\mathrm{BP}$ concentration, $0.05 \mathrm{~mol} \mathrm{~L}^{-1}$; solvent, acetone; volume of reaction solution, $5 \mu \mathrm{L}$; UV intensity, $6900 \mu \mathrm{W} \mathrm{cm}{ }^{-2}$.

occurred to some extent in this heterogeneous photografting system, which offered contribution to the rate of the overall polymerization. It can be found from Table I that the lower the reaction temperature was, the more the homopolymerization was. So elevating the temperature is one of the means to reduce the homopolymerization and accordingly promote the graft polymerization.

Some other researchers have reduced the homopolymerization to some degree by adding some additives (for example, water) or multi-functional monomers into the photografting system, hence the grafting efficiency was enhanced. ${ }^{3}$ In this study, the suitable methods to improve the grafting efficiency were found to beintroducing the electron donor monomer, keeping the molar ratio of MAH to BVE $1: 1$, using hydrogen abstractable photoinitiator BP, far UV radiation and high UV intensity, high temperature and the appropriate solvent with good affinity towards the substrate. In conclu-

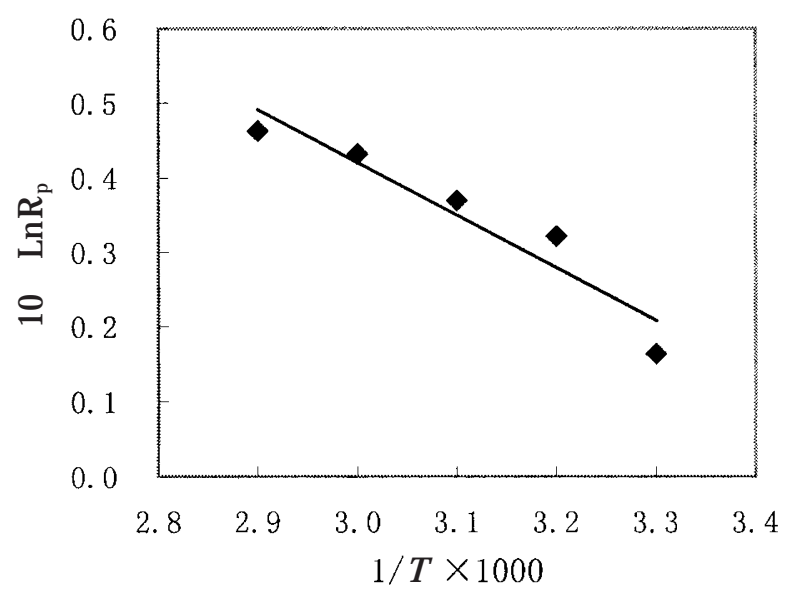

(A)

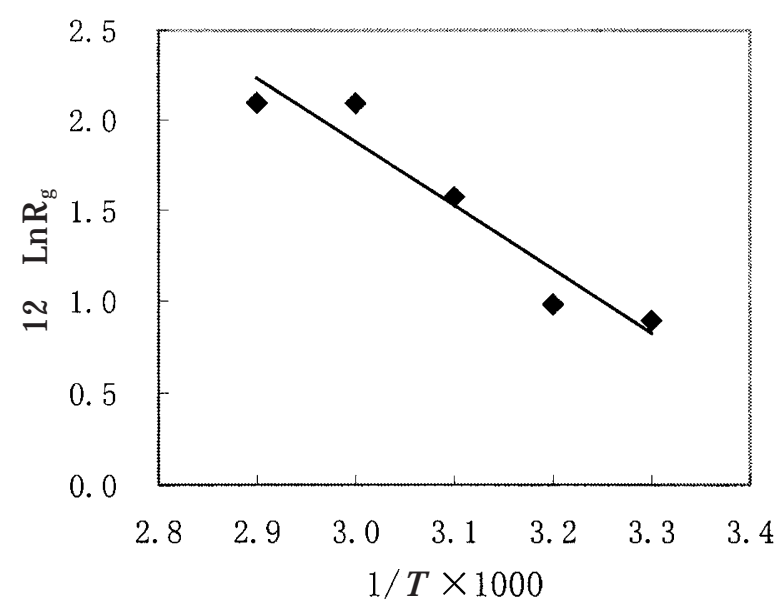

(B)

Figure 3. Plots of the $\operatorname{Ln} R_{\mathrm{p}} v s .1 / T(\mathrm{~A})$ and $\operatorname{Ln} R_{\mathrm{g}} v s .1 / T(\mathrm{~B})$.

sion, how to reduce the homopolymerization and improve the grafting efficiency is one of the major problems to be solved for the surface photografting polymerization.

As for the second characteristic, it implies that the activation energy of the grafting polymerization (Eag) is higher than that of the overall polymerization (Eap). With the data $R_{\mathrm{p}}$ and $R_{\mathrm{g}}$ at various temperatures, the plots of $\operatorname{Ln} R_{\mathrm{p}} v s .1 / T$ and $\operatorname{Ln} R_{\mathrm{g}} v s .1 / T$ could be made, as shown in Figure 3, and subsequently the activation energies were calculated according to the Arrhenius formula.

Thus, the activation energies Eap $5.9 \mathrm{~kJ} \mathrm{~mol}^{-1}$ and Eag $29.3 \mathrm{~kJ} \mathrm{~mol}^{-1}$ were obtained. It can be clearly found that Eag is nearly 4 times higher than Eap, so the influence of the temperature on $R_{\mathrm{g}}$ was much more than that on $R_{\mathrm{p}}$. In other words, it was the graft polymerization that was greatly affected by the reaction temperature while the homopolymerization was affected much less, the latter of which lowered the overall activation energy.

The reason that the photografting polymerization 


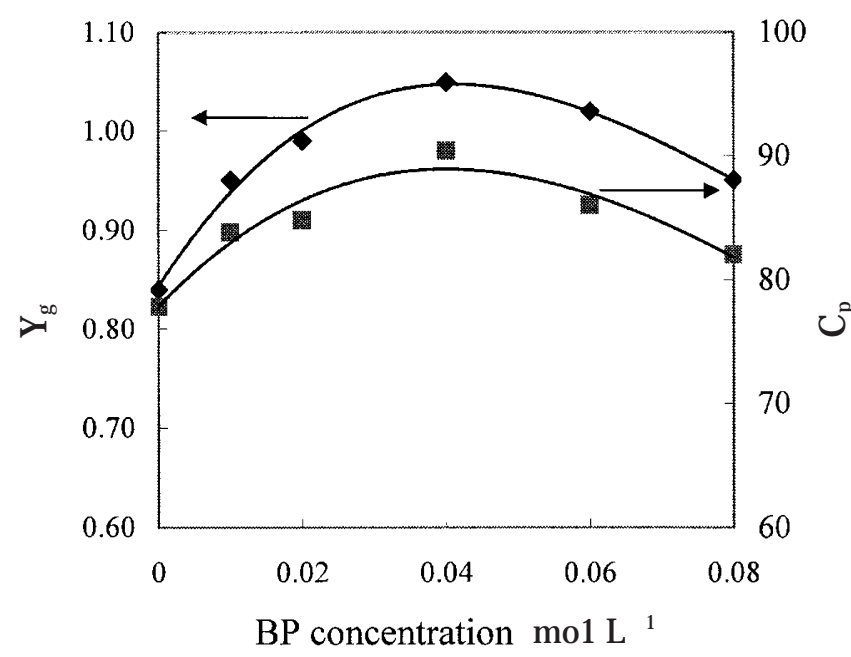

Figure 4. Effect of $\mathrm{BP}$ concentration on the photografting polymerization of MAH/BVE. Molar ratio of MAH to BVE, $1: 1$; total monomer concentration, $4 \mathrm{~mol} \mathrm{~L}^{-1}$; solvent, acetone; volume of reaction solution, $5 \mu \mathrm{L}$; reaction temperature, $60^{\circ} \mathrm{C}$; UV intensity, $8600 \mu \mathrm{W} \mathrm{cm}{ }^{-2}$; irradiation time, $60 \mathrm{~s}$.

was greatly affected by the reaction temperature can be interpreted as follows. As commonly known, the photografting polymerization includes photoinitiation process and grafting process. In the photoinitiation process, the photoinitiator absorbed UV energy and was excited, then abstracted hydrogen from the surface of the polymeric substrate; this process was affected little by the temperature. However, the grafting process was related to the temperature to much extent. On the one hand, the grafting polymerization takes place merely at the liquid-solid interface, as mentioned above, so the diffusion of the monomer and photoinitiator towards the substrate is a crucial process; when the temperature increased, the diffusion process would speed up. On the other hand, the surface free radicals were rooted on the substrate and the grafting chain free radicals were tied to the substrate, so their mobility and vibration were largely inhibited, and they would be largely activated by the higher temperature. ${ }^{3}$ As a result of these two factors, the higher reaction temperature is favorable to the graft polymerization.

\section{Initiation Performance of MAH}

$\mathrm{MAH}$, as a monomer, can also act as a photoinitiator under UV irradiation, which has been discovered and reported in our earlier article, ${ }^{4}$ and it was further confirmed in this photografting system. First of all, the effect of BP concentration on the photografting was investigated and the results were shown in Figure 4.

It can be unexpectedly seen from Figure 4 that both $C_{\mathrm{p}}$ and $Y_{\mathrm{g}}$ values were affected limitedly by the photoinitiator concentration. In the range of 0 $0.04 \mathrm{~mol} \mathrm{~L}^{-1}, C_{\mathrm{p}}$ and $Y_{\mathrm{g}}$ were improved to some ex-

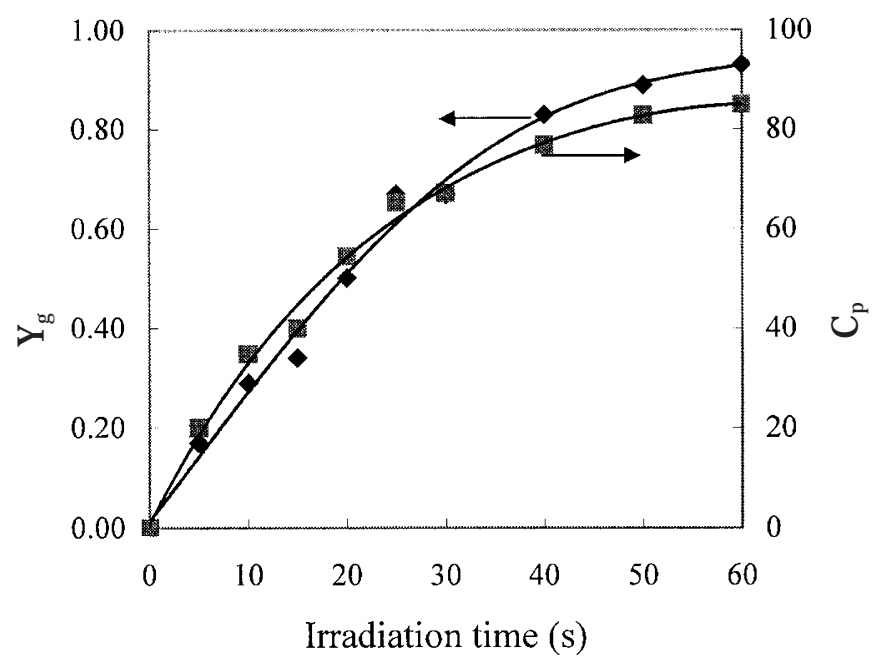

Figure 5. Performance of the photografting polymerization of $\mathrm{MAH} / \mathrm{BVE}$ without photoinitiator. Molar ratio of MAH to BVE, $1: 1$; total monomer concentration, $4 \mathrm{~mol} \mathrm{~L}^{-1}$; solvent, acetone; volume of reaction solution, $5 \mu \mathrm{L}$; reaction temperature, $60^{\circ} \mathrm{C}$; UV intensity, $8600 \mu \mathrm{W} \mathrm{cm}^{-2}$; irradiation time, $60 \mathrm{~s}$.

tent along with the photoinitiator concentration, due to the increase of the amount of the grafting points; after $0.04 \mathrm{~mol} \mathrm{~L}^{-1}, C_{\mathrm{p}}$ and $Y_{\mathrm{g}}$ started to decrease slightly, because too many grafting points would result in much coupling termination among the grafting chains as well as the self-screening effect. Furthermore, it was surprisingly found out that the photografting of $\mathrm{MAH} / \mathrm{BVE}$ readily underwent even in the absence of photoinitiator; for example, $C_{\mathrm{p}}$ could reach nearly $80 \%$ and $Y_{\mathrm{g}}$ was $0.84 \%$ within $1 \mathrm{~min}$, and accordingly the grafting efficiency was about $50 \%$.

In order to further confirm this phenomenon, the experiment of the photografting of MAH/BVE without any photoinitiator was designed, and the results are presented in Figure 5.

The curves in Figure 5 show that both $C_{\mathrm{p}}$ and $Y_{\mathrm{g}}$ increased smoothly along with the irradiation time, which indicated that the photografting of MAH/BVE did have readily undergone in the absence of any photoinitiator. This may offer a possibility for application to carry out the photografting polymerization without photoinitiator. Associating with our previous results ${ }^{4}$ that $\mathrm{MAH}$ itself could readily undergo photografting in the absence of any photoinitiator and acrylic acid (AA) could perform photografting in the presence of MAH (without adding photoinitiator), the initiation performance of MAH in this photografting system can be naturally deduced.

The initiation mechanism of MAH was commonly attributed to the hydrogen abstraction ability of the excited dimer of two MAH molecules $\left(\cdot \mathrm{MAH}^{+}-\right.$ $\left.{ }^{-} \mathrm{MAH} \cdot\right)^{5,6}$ and the formation of the ion-radicals has been confirmed by the detectable increasing electrical 


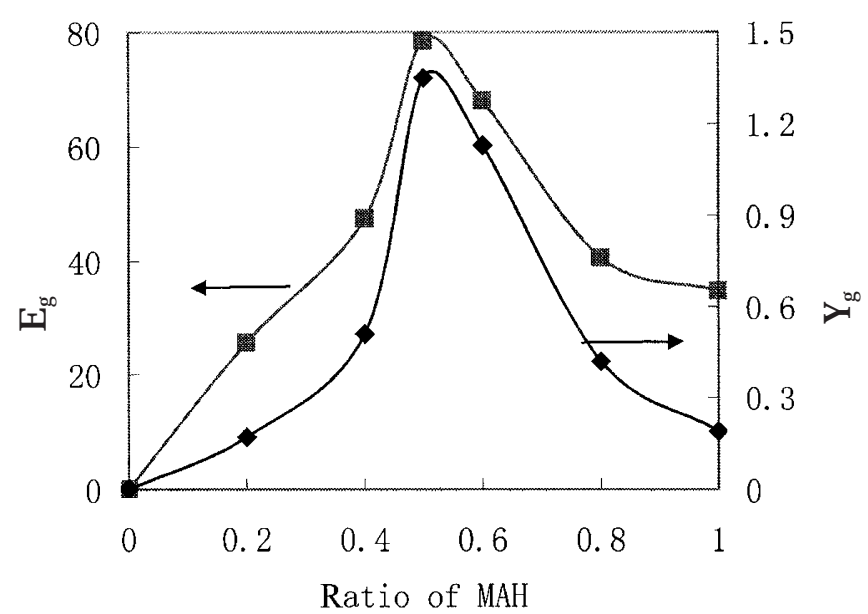

Figure 6. Effect of the molar ratio of MAH to BVE on photografting polymerization. Total monomer concentration, $4 \mathrm{~mol} \mathrm{~L}^{-1}$; BP concentration, $0.05 \mathrm{~mol} \mathrm{~L}^{-1}$; solvent, acetone; volume of reaction solution, $5 \mu \mathrm{L}$; reaction temperature, $50^{\circ} \mathrm{C}$; UV intensity, $6900 \mu \mathrm{W} \mathrm{cm}^{-2}$; irradiation time, $60 \mathrm{~s}$.

conductivity of MAH solution in dioxane under UV irradiation. ${ }^{7}$ The detailed reaction expression will be presented in the hinder part of this article.

Since the concentration of MAH was much higher than that of BP, MAH might play an important role in the initiation process, which led to the limited effect of BP concentration on the photografting performance. In addition, it was reported that the solvent acetone ${ }^{8}$ and the excited $\mathrm{CTC}^{9}$ formed between MAH and various electron donor molecules had initiation ability as well, but their effects might be slight in this reaction system. In conclusion, the initiation process of the photografting polymerization with $\mathrm{MAH} / \mathrm{BVE}$ as binary monomers, $\mathrm{BP}$ as photoinitiator and acetone as solvent is fairly complicated, which needs to be further investigated.

\section{Effect of the Electron Donor Monomer on Photograft- ing}

As mentioned in the previous article, the graft polymerization of MAH could be greatly improved by means of introducing the electron donor monomer $n$ BVE. In this study, more experiments were carried out to study this phenomenon intensively and the results are shown in Figure 6.

There are three obvious characteristics exhibited in Figure 6. 1) The grafting yield and grafting efficiency reached the highest when the molar ratio of MAH to BVE was $1: 1$, at which the concentration of CTC was the highest. 2) When the content of MAH was 0 , both $Y_{\mathrm{g}}$ and $E_{\mathrm{g}}$ were 0 , which indicated that BVE itself could not undergo radical homopolymerization. 3) When the content of BVE was 0 , MAH itself could perform graft polymerization to some degree.

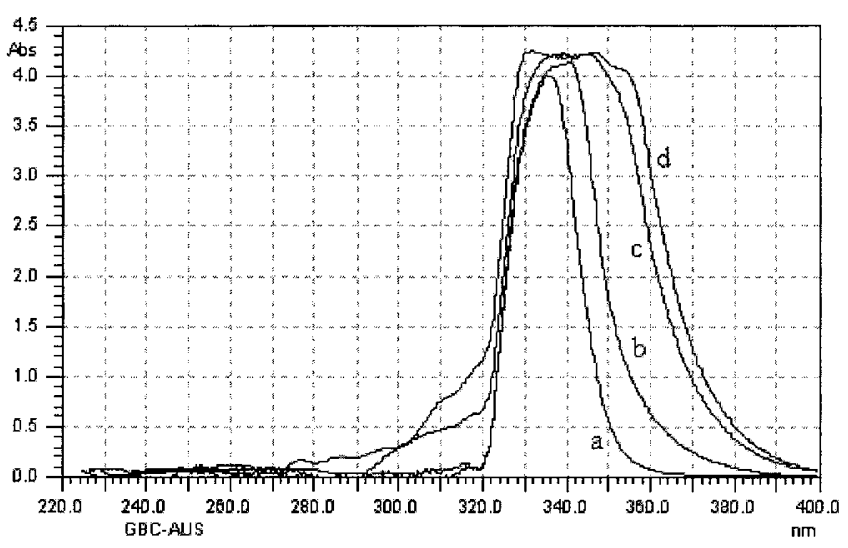

Figure 7. UV spectra of CTC in different solutions containing various amount of BVE. MAH concentration was kept constant at $1.0 \mathrm{~mol} \mathrm{~L}^{-1}$; BVE concentration was varied - ${ }^{\mathrm{a}}, 0 \mathrm{~mol} \mathrm{~L}^{-1}$; ${ }^{\mathrm{b}} 0.25 \mathrm{~mol} \mathrm{~L}^{-1}$; ${ }^{\mathrm{c}} 0.75 \mathrm{~mol} \mathrm{~L}^{-1}$; ${ }^{\mathrm{d}} 1.0 \mathrm{~mol} \mathrm{~L}^{-1}$; solvent, acetone; temperature, $25^{\circ} \mathrm{C}$.

Since BVE is a typical monomer for cationic polymerization, as commonly known, it is impossible to undergo radical homopolymerization. Due to the great steric hindrance, MAH is difficult to perform homopolymerization and only some short grafted chains could be obtained in the photografting. But MAH, as an electron acceptor $(\mathrm{e}=+2.25)$, and the introduced $\mathrm{BVE}$, as an electron donor $(\mathrm{e}=-1.3)$, are prone to form $\mathrm{CTC},{ }^{2}$ and consequently they readily undergo alternating copolymerization. So far, the formation of CTC has been popularly accepted as a major mechanism of the alternating copolymerization. In this study, we have implanted the alternating copolymerization into the surface photografting polymerization field, realizing the introduction of MAH onto the polymer substrate facilely. In short, the formation of CTC between MAH and BVE plays a crucial role in this photografting system.

\section{Measurement of CTC between MAH and $n-B V E$}

The formation of CTC can be measured by different method, and the common ones are UV spectra and ${ }^{1} \mathrm{H}$ NMR. The UV spectra of the solution containing MAH and BVE are presented in Figure 7 below.

It can be seen from Figure 7 that the highest UV absorption band $\left(\lambda_{\max }\right)$ moved to the long wavelength range (red shift) and the peak width became wider and wider along with the increase of BVE concentration. To speak in detail, in the pure MAH solution (curve a), the $\lambda_{\max }$ was about $335 \mathrm{~nm}$ and the peak width was narrower (low UV absorption); when BVE concentration increased, the CTC concentration accordingly increased, so the $\lambda_{\max }$ gradually shifted to the long wavelength range and the absorption peak got wider (high UV absorption). This is a remarkable characteristic of CTC under UV irradiation, which was once used to de- 
Table II. Chemical shifts of MAH in different solutions containing various amount of BVE*

\begin{tabular}{cccc}
\hline$[\mathrm{MAH}]\left(\mathrm{mol} \mathrm{L}^{-1}\right)^{\mathrm{a}}$ & {$[\mathrm{BVE}]\left(\mathrm{mol} \mathrm{L}^{-1}\right)^{\mathrm{b}}$} & $\delta_{\text {obsd }}(\mathrm{ppm})^{\mathrm{c}}$ & $\Delta_{\text {obsd }}(\mathrm{ppm})^{\mathrm{d}}$ \\
\hline 0.1 & 1.0 & 6.9890 & 0.0275 \\
0.1 & 2.0 & 6.9636 & 0.0529 \\
0.1 & 2.5 & 6.9412 & 0.0753 \\
0.1 & 3.0 & 6.9367 & 0.0798 \\
\hline
\end{tabular}

\footnotetext{
${ }^{*}$ Deuteriochloroform $\left(\mathrm{CDCl}_{3}\right)$ as solvent and the chemical shift of $\mathrm{CDCl}_{3}(7.24 \mathrm{ppm})$ as reference, the measurement temperature was $35^{\circ} \mathrm{C}$.

${ }^{\mathrm{a}} \mathrm{MAH}$ concentration was kept constant at $0.1 \mathrm{~mol} \mathrm{~L}^{-1}$. ${ }^{\mathrm{b}} \mathrm{BVE}$ concentration was varied and ensured $[\mathrm{MAH}] \ll[\mathrm{BVE}] .{ }^{\mathrm{c}}$ The chemical shifts of the MAH protons in a given observation. ${ }^{\mathrm{d}}$ The difference between the chemical shifts of MAH protons in the free form and in a given observation, $\delta_{\text {free }}=7.0165 \mathrm{ppm}$.
}

termine the equilibrium constant of CTC. ${ }^{10}$

The formation of CTC in the photografting system can also be measured by ${ }^{1} \mathrm{H}$ NMR and the equilibrium constant $K$ of CTC can be determined from the NMR data according to the Hanna and Ashbaugh eqution. ${ }^{11}$ $K$ can be defined by eq 2 :

$$
\begin{gathered}
\mathrm{MAH}+\mathrm{BVE} \rightleftharpoons \mathrm{CTC} \\
K=\frac{[\mathrm{CTC}]}{[\mathrm{MAH}][\mathrm{BVE}]}
\end{gathered}
$$

With the assumption of rapid exchange between complexed and free states of MAH molecules, the observed chemical shifts of their protons are the weighted average of the shifts corresponding to these two states, ${ }^{12}$ that is:

$$
\begin{aligned}
\delta_{\mathrm{obsd}}^{\mathrm{MAH}}= & \delta_{\mathrm{fr}}^{\mathrm{MAH}} \frac{[\mathrm{MAH}]}{[\mathrm{MAH}]+[\mathrm{CTC}]} \\
& +\delta_{\mathrm{c}}^{\mathrm{MAH}} \frac{[\mathrm{CTC}]}{[\mathrm{MAH}]+[\mathrm{CTC}]}
\end{aligned}
$$

where $\delta_{\text {obsd }}^{\mathrm{MAH}}, \delta_{\mathrm{fr}}^{\mathrm{MAH}}$, and $\delta_{\mathrm{c}}^{\mathrm{MAH}}$ are the shifts of the MAH protons in a given observation, in the free form and in the pure complex, respectively.

If the initial concentrations are chosen as $[\mathrm{MAH}]_{\mathrm{o}} \ll[\mathrm{BVE}]_{\mathrm{o}}$, eq 3 can be written as

$$
\frac{1}{\Delta_{\text {obsd }}}=\frac{1}{K \Delta_{\mathrm{c}}} \frac{1}{[\mathrm{BVE}]}+\frac{1}{\Delta_{\mathrm{c}}}
$$

where

$$
\begin{aligned}
\Delta_{\mathrm{obsd}} & =\delta_{\mathrm{fr}}^{\mathrm{MAH}}-\delta_{\mathrm{obsd}}^{\mathrm{MAH}} \\
\Delta_{\mathrm{c}} & =\delta_{\mathrm{fr}}^{\mathrm{MAH}}-\delta_{\mathrm{c}}^{\mathrm{MAH}}
\end{aligned}
$$

This is the well known Hanna-Ashbaugh equation.

In this experiment, the concentration of MAH was kept constant at $0.1 \mathrm{~mol} \mathrm{~L}^{-1}$, while that of BVE was varied and ensured $[\mathrm{MAH}]_{\mathrm{o}} \ll[\mathrm{BVE}]_{\mathrm{o}}$. From the NMR spectra, the chemical shifts were obtained, which are summarized in Table II.

From Table II it can be found that the chemical shifts of the protons in MAH molecules decreased gradually

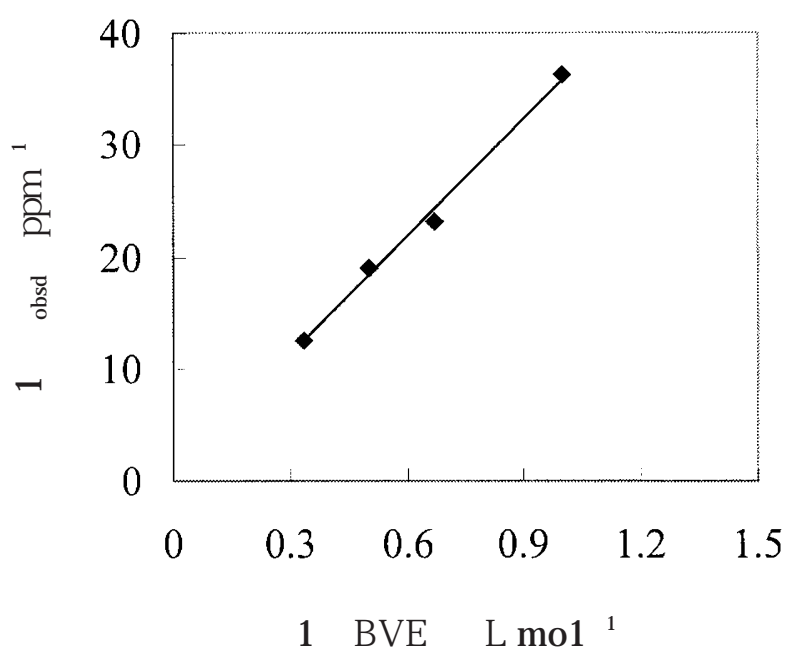

Figure 8. Plot of $1 / \Delta_{\text {obsd }} v s .1 /[\mathrm{BVE}]$.

along with the elevation of BVE concentration. In the NMR spectra, the peaks of the protons in MAH became lower and lower, while those of BVE became higher and higher without changing chemical shifts. This is another evidence of the formation of CTC in this reaction system. With the data from Table II, a plot of $1 / \Delta_{\text {obsd }} v s .1 /$ [BVE] could be made according to eq 4.

Thus the equilibrium constant $0.019 \mathrm{~L} \mathrm{~mol}^{-1}$ was obtained. The value is relatively small in comparison with the other pairs of electron donor and acceptor in the references, although the complex effect between MAH and BVE is expected to be strong. This may be ascribed to the polar solvent chloroform used in the measurement and the relatively high temperature. But the CTC concentration is considered to increase under UV irradiation accompanied by the charge transfer transition, so the CTC concentration is supposed to be higher in the photografting process. The remarkable red shift of $\lambda_{\max }$ and the increasing UV absorption exhibited in the UV spectra may support this assumption.

Since the structure of CTC has always been argued for years, the schematic formula of CTC shown as follows was obtained after referring to the relevant reports. ${ }^{13,14}$ 


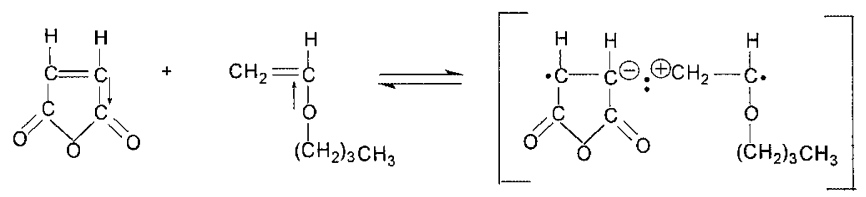

As for the mechanism of the favorable effect of CTC on the alternating copolymerization, there has always been a discussion for years. The common viewpoint concerns the expanding conjugate system between the electron donor and acceptor, which reduces the energy for the charge separation, resulting easily in the free radical and ion under heat and irradiation and accordingly leading to the smooth alternating copolymerization. In our present work, we just implant the alternating copolymerization into the graft polymerization system by means of introducing the electron donor monomer BVE, so as to graft MAH onto the polymer substrate facilely.

\section{Reaction Process of the Photografting of MAH/BVE}

Based on the results and discussion in these two articles, the surface photografting polymerization of $\mathrm{MAH} / \mathrm{BVE}$ can be outlined. The whole process involves three periods - the photoinitiation process at the liquid-solid interface, the photopolymerization process including photografting and homopolymerization, the termination process of various coupling reactions.

Photoinitiation. In the initiation process, both $\mathrm{MAH}$ and BP played an important role, as have been demonstrated above.

When irradiated by UV, BP was excited to the single state $\left(\mathrm{BP}^{\mathrm{S}}\right)$ and immediately relaxed to the stable triplet state $\left(\mathrm{BP}^{\mathrm{T}}\right)$ through intersystem crossing (ISC), then $\mathrm{BP}^{\mathrm{T}}$ abstracted hydrogen from the surface of the polymeric substrate. Thus the surface free radicals and semibenzopinacol free radicals were generated.

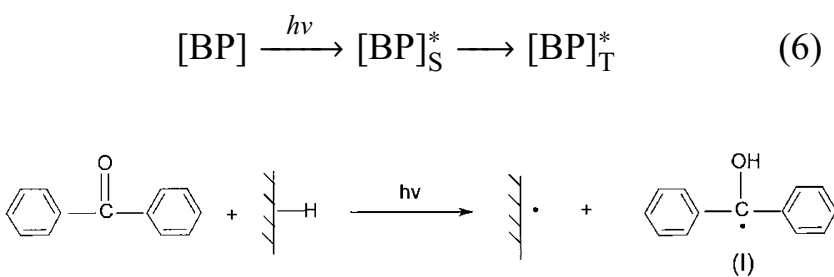

With respect to MAH, the excited dimer of two MAH molecules ( $\left.\cdot \mathrm{MAH}^{+}-{ }^{-} \mathrm{MAH} \cdot\right)$ formed firstly under UV irradiation; and secondly, the exciplex abstracted hydrogen from the substrate as BP did.

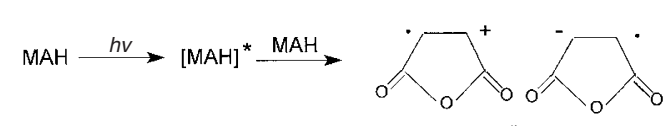

(II)

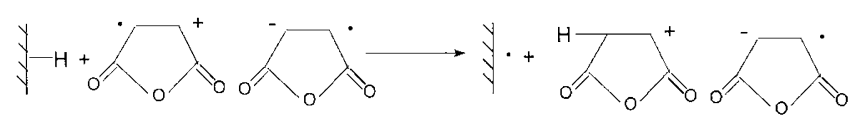

(III)

Photopolymerization. The reactions in this system involve grafting polymerization at the liquid-solid interface and homopolymerization in the liquid phase. To speak in detail, the surface free radicals rooted on the substrate will initiate the grafting polymerization, while the small radicals (R·) including (I), (II), and (III) will initiate the homopolymerization, which can be expressed as follows.

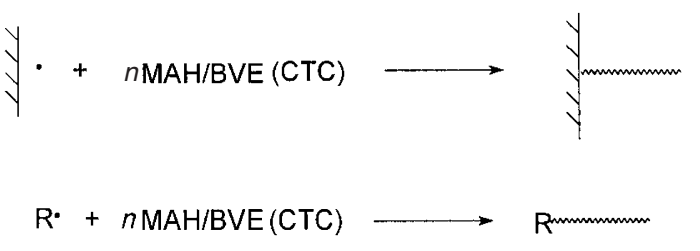

Coupling Termination. The termination process involves many coupling reactions, including grafting chains and small free radicals, homopolymer chains and small free radicals, homopolymer chains and grafting chains, homopolymer chains themselves, grafting chains themselves. Among those, the coupling termination between homopolymer chains and grafting chains is another mode of the grafting to the substrate, which may result in more grafting yield.
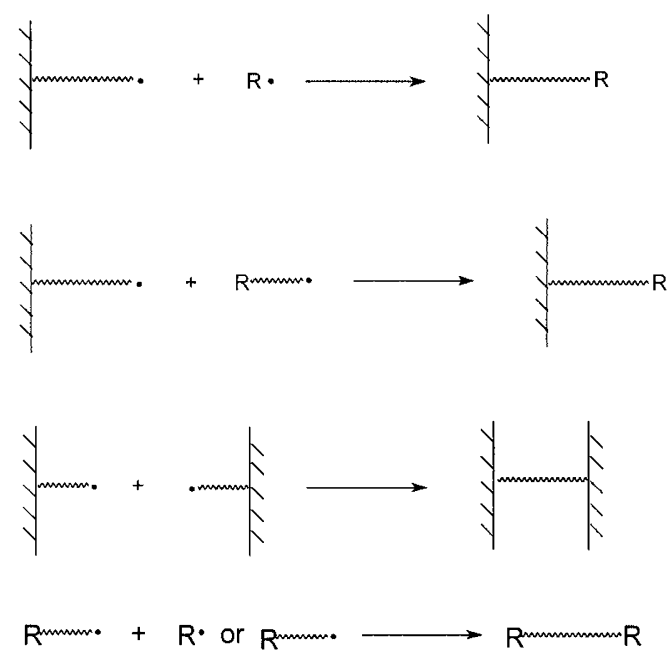

\section{CONCLUSIONS}

(1) The reaction temperature has little effect on the overall polymerization while has remarkable effect on the graft polymerization.

(2) The photografting polymerization occurs merely at the liquid-solid interface and the homopolymerization exists in the liquid phase to some extent. 
(3) Besides BP, the monomer MAH can act as a photoinitiator as well in this photografting polymerization system.

(4) The introduced electron donor monomer BVE is prone to form CTC with $\mathrm{MAH}$, which is favorable to the graft polymerization of MAH.

Acknowledgment. This research has been supported by Special Funds for Major State Basic Research Projects (G1999064800) and the Chinese Outstanding Youth Foundation (20025415), which are gratefully acknowledged.

\section{REFERENCES}

1. C. M. Xing, J. P. Deng, and W. T. Yang, Polym. J., 34, 801 (2002).

2. P. D. Bartlett and K. Nozaki, J. Am. Chem. Soc., 68, 1495 (1946).

3. W. T. Yang and B. Rånby, J. Appl. Polym. Sci., 62, 545 (1996).

4. J. P. Deng and W. T. Yang J. Polym. Sci., Part A:Polym. chem.,
39, 3246 (2001).

5. N. G. Gaylord, J. Macromol. Sci., Rev. Macromol. Chem. Pys., 13, 235 (1975).

6. I. Nagahiro, K. Nishihara, and N. Sakota, J. Polym. Sci., Polym. Chem. Ed., 12, 785 (1974).

7. K. Takakura, K. Hayashi, and S. Okamura, J. Polym. Sci., A-1, polym. Chem., 4, 1747 (1966).

8. K. Allmer, A. Hult, and B. Rånby, J. Polym. Sci., Part A:Polym. chem., 26, 2099 (1988).

9. A. Torres, F. Castaño, and J. M. Alvarino, Makromol. Chem., 179, 2653 (1978).

10. H. A. Benessi and J. H. Hildebrand, J. Am. Chem. Soc., 71, 2703 (1949).

11. M. W. Hanna and A. L. Ashbaugh, J. Phys. Chem., 68, 811 (1964).

12. D. Ghesquiere, R. Arnaud, and C. Caze, J. Phys. Chem., 83, 2029 (1979).

13. L. F. Zhang and B. H. Guo, Acta Polymerica Sinica, 3, 338 (2001).

14. L. P. Elling, "Advances in Macromolecular Chemistry", Academic Press, Inc. New York, NY, 1968, p 169. 